\title{
Nutlin-3a suppresses poly (ADP-ribose) polymerase 1 by mechanisms different from conventional PARP1 suppressors in a human breast cancer cell line
}

\author{
Masaki Kobayashi, ${ }^{1,2, *}$, Yuka Ishizaki ${ }^{1, *}$, Mika Owaki ${ }^{1, *}$, Yoko Matsumoto ${ }^{1}$, Yuri \\ Kakiyama ${ }^{1}$, Shunsuke Hoshino ${ }^{1,2}$, Ryoma Tagawa ${ }^{1}$, Yuka Sudo ${ }^{2}$, Naoyuki Okita ${ }^{3}$, \\ Kazunori Akimoto ${ }^{2,4}$ and Yoshikazu Higami ${ }^{1,2}$ \\ ${ }^{1}$ Laboratory of Molecular Pathology \& Metabolic Disease, Faculty of Pharmaceutical Sciences, Tokyo University of Science, \\ Noda, Chiba 278-8510, Japan \\ ${ }^{2}$ Translational Research Center, Research Institute of Science and Technology, Tokyo University of Science, Noda, Chiba 278- \\ 8510, Japan \\ ${ }^{3}$ Division of Pathological Biochemistry, Faculty of Pharmaceutical Sciences, Sanyo-Onoda City University, Sanyo-onoda, \\ Yamaguchi 756-0884, Japan \\ ${ }^{4}$ Laboratory of Medicinal and Life Science, Faculty of Pharmaceutical Sciences, Tokyo University of Science, Noda, Chiba \\ 278-8510, Japan \\ * Co-first authors \\ Correspondence to: Masaki Kobayashi, email: kobayashim@rs.tus.ac.jp \\ Yoshikazu Higami, email: higami@rs.noda.tus.ac.jp \\ Keywords: nutlin-3a; PARP1; breast cancer; proteasomal degradation; autoPARylation \\ Received: December 21, $2019 \quad$ Accepted: April 14, $2020 \quad$ Published: May 05, 2020
}

Copyright: Kobayashi et al. This is an open-access article distributed under the terms of the Creative Commons Attribution License 3.0 (CC BY 3.0), which permits unrestricted use, distribution, and reproduction in any medium, provided the original author and source are credited.

ABSTRACT

Poly (ADP-ribose) polymerase 1 (PARP1) plays important roles in single strand DNA repair. PARP1 inhibitors enhance the effects of DNA damaging drugs in homologous recombination-deficient tumors including tumors with breast cancer susceptibility gene (BRCA1) mutation. Nutlin-3a, an analog of cis-imidazoline, inhibits degradation of murine double minute 2 (MDM2) and stabilizes p53. We previously reported that nutlin-3a induces PARP1 degradation in p53-dependent manner in mouse fibroblasts, suggesting nutlin-3a may be a PARP1 suppressor. Here, we investigated the effects of nutlin-3a on PARP1 in MCF-7, a human breast cancer cell line. Consistent with our previous results, nutlin-3a reduced PARP1 levels in doseand time-dependent manners in MCF-7 cells, but this reduction was suppressed in p53 knockdown cells. RITA, a p53 stabilizer that binds to p53 itself, failed to reduce PARP1 protein levels. Moreover, transient MDM2 knockdown repressed nutlin-3amediated PARP1 reduction. The MG132 proteasome inhibitor, and knockdown of checkpoint with forkhead and ring finger domains (CHFR) and ring finger protein 146 (RNF146), E3 ubiquitin ligases targeting PARP1, suppressed nutlin-3a-induced PARP1 reduction. Short-term nutlin-3a treatment elevated the levels of PARylated PARP1, suggesting nutlin-3a promoted PARylation of PARP1, thereby inducing its proteasomal degradation. Furthermore, nutlin-3a-induced PARP1 degradation enhanced DNA-damaging effects of cisplatin in BRCA1 knockdown cells. Our study revealed that nutlin-3a is a PARP1 suppressor that induces PARP1 proteasomal degradation by binding to MDM2 and promoting autoPARylation of PARP1. Further analysis of the mechanisms in nutlin-3a-induced PARP1 degradation may lead to the development of novel PARP1 suppressors applicable for cancers with BRCA1 mutation. 


\section{INTRODUCTION}

The poly (ADP-ribose) polymerase (PARP) family consists of 17 enzymes and functions in several cellular processes including DNA recombination and repair, cellular proliferation, apoptosis in ischemic conditions and necrotic cell death [1-3]. PARPs catalyze poly (ADP-ribosyl) ation (PARylation) of target proteins with intracellular nicotinamide adenine dinucleotide $\left(\mathrm{NAD}^{+}\right)$. PARP1 is activated by DNA damage caused by free radicals or other agents and plays an important role in single strand DNA repair through the base excision pathway [1-3]. Activated PARP1 PARylates and recruits DNA repair factors such as X-ray repair crosscomplementing gene 1 (XRCC1), DNA ligase III and polynucleotide kinase (PNK) to damaged sites, resulting in DNA repair [4]. PARP1 is also involved in transcriptional regulation and maintenance of genomic integrity via inducing chromatin structural change by PARylation of histones and DNA demethylase [5].

Previous studies have shown that PARylation enhances the ubiquitination of substrate proteins and thus promotes proteasomal degradation of several target proteins. Some E3 ubiquitin ligases have been reported to recognize the PAR-group on target proteins via the WWE or PBZ domain, resulting in increased target protein ubiquitination [6, 7]. Furthermore, PARP1 is regulated by ubiquitination-mediated proteosomal degradation, and ubiquitination of PARP1 has been shown to be dependent on PARylation by PARP1 itself, in other words via autoPARylation $[8,9]$. For example, ring finger protein 146 (RNF146) induces poly-ubiquitination and degradation of autoPARylated PARP1, regulating the DNA damage response [10]. Likewise, checkpoint with forkhead and ring finger domains (CHFR) preferentially interacts with autoPARylated PARP1 under mitotic stress conditions and then induces PARP1 degradation via the ubiquitin-proteasome system [11]. These findings suggest that autoPARylation is important for the degradation of PARP1 protein.

Targeting the PARP1-mediated DNA repair pathway has recently received considerable attention as an approach for enhancing the effects of anti-cancer drugs and radiation therapy [12]. PARP1 inhibitors have been proven to enhance the sensitivity of homologous recombination (HR)-deficient tumors to DNA-damaging agents $[13,14]$. PARP1 inhibitors are expected to serve as therapeutic agents for various cancers such as breast cancer susceptibility gene 1 (BRCA1)- and BRCA2associated hereditary breast and ovarian cancers, prostate cancer, non-small cell lung cancer, and Ewing sarcoma [13-18]. For example, olaparib, the first available and approved PARP $1 / 2$ inhibitor, significantly extended the progression-free survival of BRCA1/2 mutation-positive ovarian cancer patients in clinical trials [19]. Moreover, olaparib monotherapy has provided a significant benefit over standard therapy for patients with HER2-negative metastatic breast cancer and a germline $B R C A$ mutation [20]. Several studies have described mechanisms of actions of PARP inhibitors other than via DNA repair pathways, including metastasis, tumor angiogenesis and neuronal death $[18,21,22]$. Some available PARP1 inhibitors, many of which contain a nicotinamide/ benzamide pharmacophore group, competitively inhibit the binding of PARP1 to NAD ${ }^{+}[23,24]$.

Nutlin-3a, an analog of cis-imidazoline, potently binds the $\mathrm{p} 53$-binding domain in murine double minute 2 (MDM2), an E3 ubiquitin ligase for $\mathrm{p} 53$ tumor suppressor. Nutlin-3a interrupts the interaction between MDM2 and p53 and stabilizes p53 [25]. These cis-imidazoline analogs exhibit an inhibitory effect on the growth of various cancer cell lines and are in early phase clinical trials [26]. We previously reported that nutlin-3a induces proteasomedependent PARP1 protein degradation in $\mathrm{p} 53$-dependent manner in mouse fibroblasts and increases p53 protein levels [27]. These discoveries provide the possibility of nutlin-3a as a PARP1 suppressor with a novel molecular mechanism. In the present study, we investigated this possibility by exploring the mechanisms of PARP1 reduction by nutlin-3a using the MCF-7 human breast cancer cell line.

\section{RESULTS}

\section{Nutlin-3a downregulates PARP1 proteins levels in human breast cancer cells in a p53-dependent manner}

In this study, we used the MCF-7 breast cancer cell line (p53 wild-type; estrogen receptor $(+)$; progesterone receptor $(+)$; Her2 $(-)$ ), which is widely used by many researchers. Treatment of MCF-7 cells with $5 \mu \mathrm{M}$ and 25 $\mu \mathrm{M}$ nutlin-3a reduced PARP1 protein levels and increased p53 protein in a dose-dependent manner (Figure 1A). In contrast, $100 \mu \mathrm{M}$ nutlin-3a induced cleavage of PARP1 and failed to increase p53 protein. Consistent with these results, MCF-7 cells treated with $100 \mu \mathrm{M}$ nutlin-3a were detached from the culture dish, appearing to undergo cell death (data not shown). We did not detect cleaved Caspase 7 (CASP7) at any concentration of nutlin-3a (Figure 1A). We also found that nutlin-3a reduced PARP1 protein levels and exerted no influence on the cleavage of both PARP1 and CASP7 over $48 \mathrm{~h}$ in a time-dependent manner (Figure 1B).

We previously reported that nutlin-3a-induced reduction of PARP1 proteins occurs in a p53-dependent manner [27]. Hence, we generated MCF-7 cells expressing shRNA against TP53 to evaluate the p53-dependency in more detail. Down-regulation of p53 protein levels was confirmed in MCF-7/shTP53 cells (Figure 1C). Nutlin3a treatment reduced PARP1 protein level in MCF-7 cells, but not in MCF-7/shTP53 cells (Figure 1C). Both 
cell lines exhibited no change in cleaved CASP7 levels after treatment of nutlin-3a. These results indicate that the nutlin-3a-induced reduction of PARP1 protein was dependent on p53 in human breast cancer cells but did not induce cell death, as observed in mouse fibroblasts.

\section{MDM2 is required for nutlin-3a-mediated reduction of PARP1 protein}

RITA has been shown to stabilize p53 by directly binding to p53 [28], unlike nutlin-3a, which stabilizes p53 by interacting with MDM2. We thus next examined the effect of RITA on PARP1 protein levels. RITA treatment stabilized p53 in MCF-7 cells, but interestingly increased levels of a cleaved form of PARP1 rather than reduced PARP1 levels (Figure 2A), suggesting that an increased amount of p53 itself is not critical for the reduction of PARP1 protein. In addition, RITA upregulated the mRNA level of $M D M 2$, and this increase was more prominent after treatment with nutlin-3a (Figure $2 \mathrm{~B}$ and 2C). We then performed transient knockdown (KD) of MDM2 in MCF7 cells using siRNA (Figure 2D) and examined the effect of nutlin-3a-induced reduction of PARP1 protein. MDM2 KD suppressed the nutlin-3a-induced decrease of PARP1 protein (Figure 2E). These results suggested that MDM2 is critical for nutlin-3a-induced PARP1 reduction.

\section{Nutlin-3a-induced PARP1 reduction is mediated by proteasomal degradation}

We previously demonstrated that nutlin-3a-induced PARP1 reduction in a mouse fibroblast cell line occurs via proteasome degradation [27]. To examine whether proteosomal degradation is involved in MCF-7 cells, we investigated nutlin-3a-induced PARP1 reduction after treatment with MG132, a proteasome inhibitor. Consistent with the mouse fibroblast results, MG132 treatment suppressed the reduction of PARP1 proteins by nutlin-

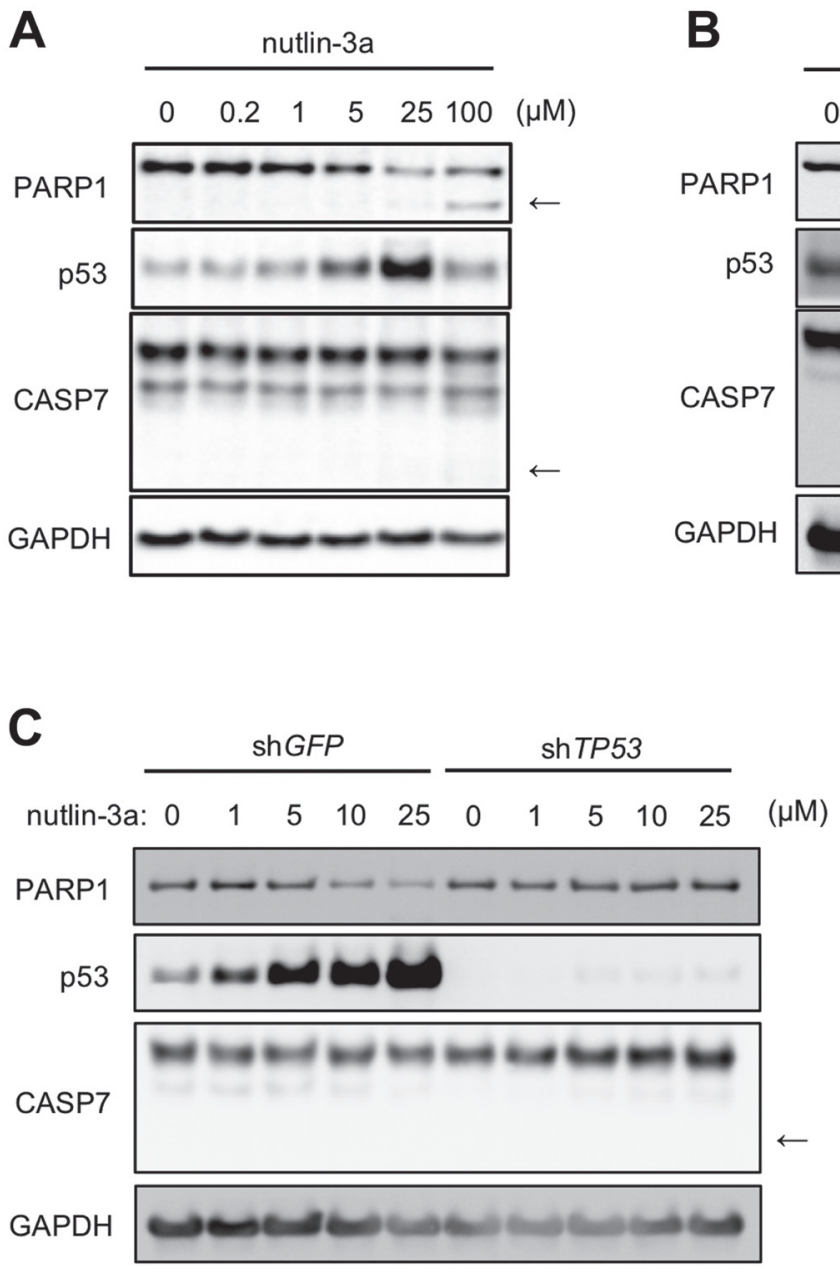

Figure 1: Nutlin-3a reduces PARP1 protein levels in MCF-7 cells, a human breast cancer cell line. (A) MCF-7 cells were treated with indicated concentrations of nutlin-3a for $24 \mathrm{~h}$. (B) MCF-7 cells were treated with $10 \mu \mathrm{M}$ nutlin-3a for the indicated times. (C) MCF-7/shGFP and MCF-7/shTP53 cells were treated with indicated concentrations of nutlin-3a for 24 h. The cell lysates were analyzed by immunoblotting using the indicated antibodies. In the PARP1 and CASP7 panels, arrows indicate apoptotic fragments. GAPDH was used as a loading control. 
A

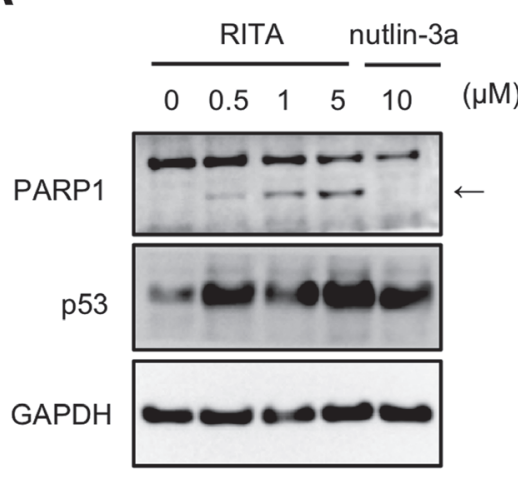

B

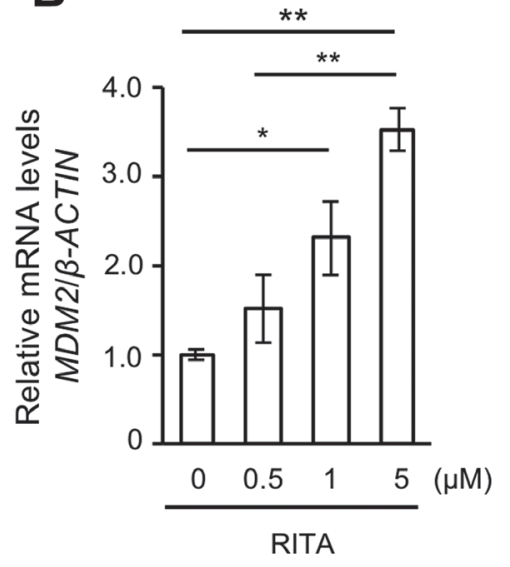

C

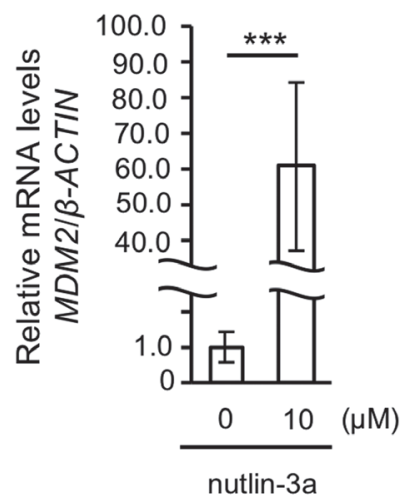

D
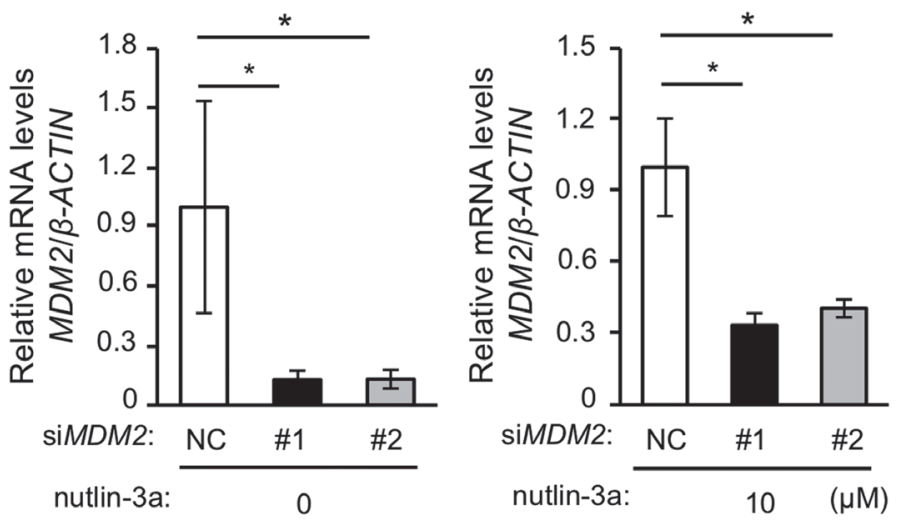

$\mathbf{E}$
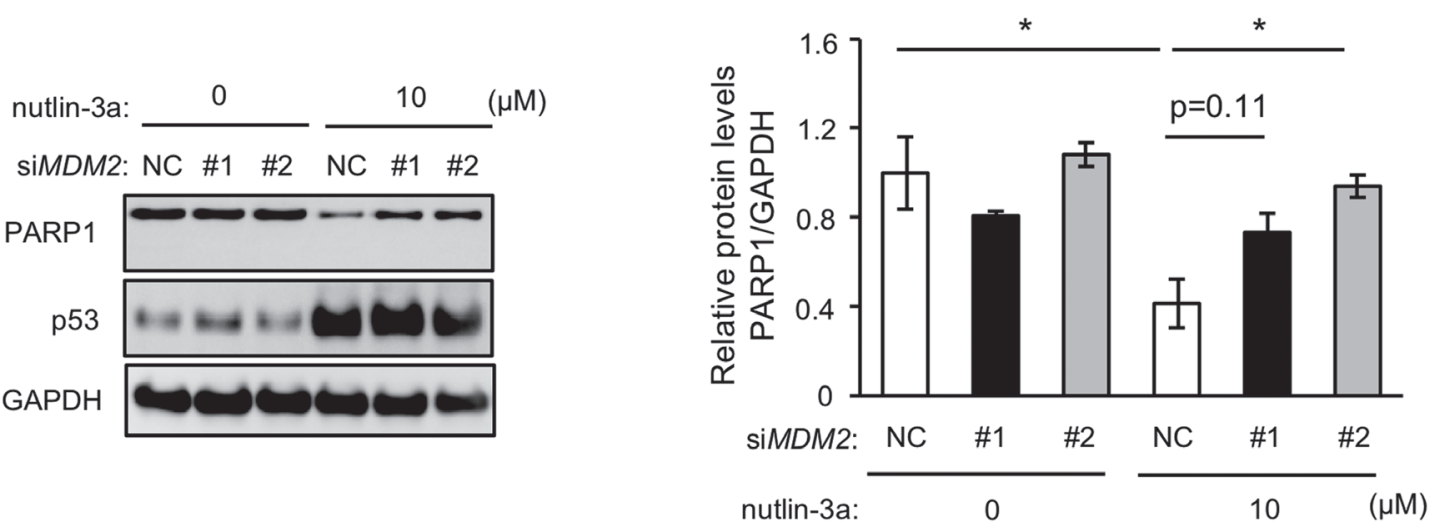

Figure 2: MDM2 is involved in nutlin-3a-induced PARP1 protein reduction. (A) MCF-7 cells were treated with indicated concentrations of RITA or $10 \mu \mathrm{M}$ nutlin-3a for $24 \mathrm{~h}$. The cell lysates were analyzed by immunoblotting using indicated antibodies. In the PARP1 panel, the arrow indicates apoptotic fragment of PARP1. (B, C) qRT-PCR was performed in MCF-7 cells treated with RITA (B) or nutlin-3a (C) at concentrations indicated in (A). (D) MCF-7 cells were transfected with two different sets of siRNA against MDM2. MDM2 levels were analyzed by qRT-PCR. $\beta$-ACTIN was used as a housekeeping gene. (E) MCF-7 cells transfected with siRNAs were treated with $10 \mu \mathrm{M}$ nutlin-3a for $24 \mathrm{~h}$. The left panel shows a representative immunoblot of three different experiments. The right panel shows the quantitative data. NC indicates negative control. GAPDH was used as a loading control. Values in (B-E) are means \pm SEM ( $n=3$; different experiments). Differences between values were analyzed by Student's $t$-test for (C), Dunnett's test for (D) or Tukey's test for (B, E) $\left({ }^{*} p<\right.$ $\left.0.05 ;{ }^{* *} p<0.01 ;{ }^{* * *} p<0.005\right)$. 
3a (Figure 3A). Furthermore, nutlin-3a did not reduce mRNA levels of PARP1 in MCF-7 cells (data not shown). E3 ubiquitin ligases play a central role in the ubiquitinproteasome system by recognizing and ubiquitinating specific substrates. We thus speculated that nutlin-3ainduced PARP1 degradation may be mediated by E3 ubiquitin ligases for PARP1, such as CHFR and RNF146 $[10,11]$. Transient KD of CHFR and RNF146 in MCF7 cells was performed using siRNA (Figure $3 \mathrm{~B}$ and $3 \mathrm{C}$ ). Nutlin-3a-induced PARP1 degradation was suppressed in CHFR KD MCF7 cells (Figure 3D) and RNF146 KD MCF7 cells (Figure 3E). These results suggested that nutlin-3a treatment promoted proteasome-mediated degradation of PARP1 proteins by CHFR and RNF146.

\section{AutoPARylation of PARP1 plays important roles in nutlin-3a-induced PARP1 degradation}

Several E3 ubiquitin ligases targeting PARP1 including CHFR and RNF146 recognize the PAR on PARylated PARP1 protein $[10,11]$. Other studies reported that PARP1 has autoPARylation activity $[8,9]$. Thus, we hypothesized that the nutlin-3a-induced PARP1 protein degradation may involve the targeting of E3 ubiquitin ligases to PARylated PARP1. We found that PJ34 and olaparib, which are PARP1/2 inhibitors that impair PARP1 activity via competitive inhibition of the binding of PARP1 to $\mathrm{NAD}^{+}$, suppressed nutlin-3a-induced degradation of PARP1 protein. These results implied that the action of nutlin-3a may be dependent on the PARylation activity of PARP protein itself (Figure 4A and 4B). In addition, to evaluate the effect of nutlin-3a on autoPARylation in nutlin-3a-induced PARP1 degradation, we examined changes in PARylated PARP1 levels in a time course assay. Several studies have shown that PARylated PARP1 bands are detected in molecular weights ranging from 100 $\mathrm{kDa}-200 \mathrm{kDa}$ by immunoblotting of whole cell extracts with the anti-PAR antibody [29-32]. We were also able to detect PARylated PARP1 using immunoblotting and found that short-term treatment of nutlin-3a enhanced PARylated PARP1 levels prior to PARP1 degradation (Figure 4C). These results suggested that autoPARylation of PARP1 contributed to nutlin-3a-induced PARP1 degradation.

\section{Nutlin-3a enhances the effects of a DNA damaging agent in BRCA1 knockdown MCF-7 cells}

To evaluate whether nutlin-3a could serve as a PARP suppressor against BRCA1-associated hereditary breast cancer, we examined the effects of nutlin-3a in MCF-7 cells expressing shRNA against BRCA1 (MCF-7/ $\mathrm{sh} B R C A 1)$ or GFP (MCF-7/shGFP), used as a negative control. In MCF-7/shBRCA1 cells with confirmed BRCA1 knockdown, nutlin-3a-induced PARP1 degradation was partially inhibited (Figure 5A, 5B). We next compared cell viability between $\mathrm{MCF}-7 / \mathrm{sh} B R C A 1$ and $\mathrm{MCF}-7 /$ shGFP cells treated with cisplatin, a DNA damaging agent, or cisplatin combined with nutlin-3a for $24 \mathrm{~h}$ after pretreatment with nutlin-3a for $12 \mathrm{~h}$. The results showed that combination treatment of cisplatin and nutlin-3a decreased cell viability in $\mathrm{MCF}-7 / \mathrm{sh} B R C A 1$ cells, but not in $\mathrm{MCF}-7 / \mathrm{sh}$ GFP cells (Figure 5C). These results suggested that nutlin-3a may enhance the effects of DNA damaging agents in BRCA1-mutated breast cancer cells.

\section{DISCUSSION}

In the present study, we confirmed that nutlin-3a decreased PARP1 protein levels via the proteasome in a p53-dependent manner in MCF-7 cells, similar to its activity in mouse fibroblasts. We previously demonstrated that p53 overexpression has no effect on PARP1 protein levels, indicating that stabilized p53 is not crucial for nutlin-3a-induced degradation of PARP1 [27]. Our results with RITA were consistent with this previous report. Furthermore, both nutlin-3a and RITA upregulated MDM2 levels in MCF-7 cells, probably from the transcriptional activation by accumulated p53, the extent of which was more prominent in cells treated with nutlin-3a. We found that knockdown of MDM2 also inhibited nutlin-3ainduced degradation of PARP1, underscoring the important role of MDM2 in the action of nutlin-3a on PARP1. This action mechanism is unclear at present, but we propose one possibility. Several previous reports have identified effects of nutlin-3a on MDM2 other than inhibiting p53 degradation. Wallace and colleagues found that in addition to MDM2 activities in the ubiquitin-proteasome system, MDM2 also activates target proteins through an allosteric mechanism [33]. The authors indicated that nutlin-3a can act as an allosteric agonist by affecting multiple MDM2 binding sites, as well as a p53 stabilizer [33]. Additionally, Nicholson and colleagues performed proteome analysis of MCF-7 cells treated with nutlin-3a and identified several novel proteins that interact with allosterically altered MDM2, such as nucleophosmin [34]. Notably, another report showed that nucleophosmin interacts with PARP1, although the contribution of nucleophosmin to PARP1 stability or activity is unclear [35]. Although the possibility that MDM2 might directly target PARP1 cannot be entirely ruled out, these studies suggest that nutlin-3ainduced PARP1 degradation might involve protein profile changes that result from the allosteric effects of nutlin-3a on MDM2. Based on these studies and our current data, we speculate that the binding of nutlin-3a to MDM2 can enhance the transcription of MDM2 via accumulated p53 and simultaneously induce allosteric alternations of increased MDM2, and this combination may cause reduced PARP1 protein levels.

We found that CHFR and RNF146 were involved in the effects of nutlin-3a using a knockdown approach. CHFR has a single PAR-binding zinc finger (PBZ), which 
A
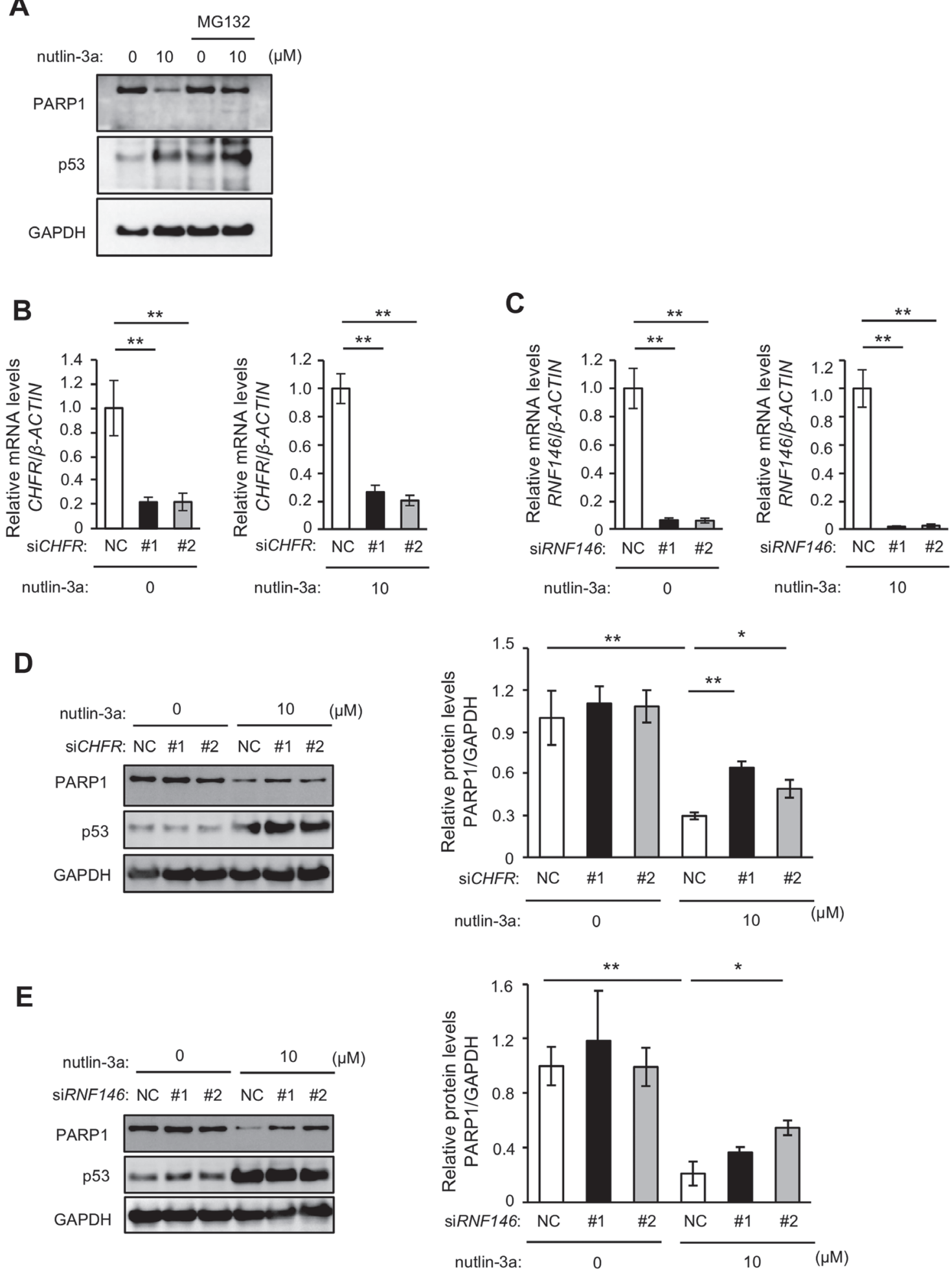

Figure 3: Nutlin-3a-induced PARP1 protein reduction is mediated by proteasomal degradation. (A) MCF-7 cells were treated with $10 \mu \mathrm{M}$ nutlin-3a for $24 \mathrm{~h}$. The proteasome inhibitor MG132 was directly added at $8 \mathrm{~h}$ after treatment with nutlin-3a. The cell lysates were analyzed by immunoblotting using indicated antibodies. (B, C) MCF-7 cells were transfected with two sets of siRNA against CHFR or RNF146. CHFR (B) and RNF146 (C) levels were analyzed by qRT-PCR. $\beta$-ACTIN was used as a housekeeping gene. (D, E) MCF-7 cells transfected with siRNAs were treated with $10 \mu \mathrm{M}$ nutlin-3a for $24 \mathrm{~h}$. The left panels show representative immunoblotting images of three different experiments. The right panels show the quantitative data. GAPDH was used as a loading control. Values in (B-E) are means $\pm \operatorname{SEM}(n=3$; different experiments). Differences between values were analyzed by Dunnett's test for (B, C) or Tukey's test for (D, E) $\left({ }^{*} p<0.05,{ }^{* *} p<0.01\right)$. 
is a PAR-binding motif [31]. RNF146 possesses the WWE domain, which contains four residues critical for binding to PAR [36]. These E3 ubiquitin ligases target PARP1 by recognizing and polyubiquitinating PARylated PARP1 $[10,11]$. Our results of combination treatment of nutlin$3 a$ with PJ34 or olaparib indicated that autoPARylation can contribute to nutlin-3a-induced PARP1 degradation. Of note, short-term treatment of nutlin-3a transiently enhanced PARylation of PARP1, whereas these levels were thereafter reduced in correlation with PARP1 protein levels. These data indicate that nutlin-3a might promote autoPARylation of PARP1 and subsequently induce PARP1 degradation by PARylation-associated targeting of E3 ubiquitin ligases. AutoPARylation of PARP1 is generally involved in various stress responses, including the DNA damage response and the heat shock response $[37,38]$. Although the detailed mechanisms and regulation of autoPARylation of PARP1 currently remain to be explained, we propose the following putative mechanism. AutoPARylation of PARP1 is reportedly negatively regulated by PAR glycohydrolase (PARG), an enzyme responsible for the degradation of PAR [39]. In addition, a previous study demonstrated that PARG undergoes proteasomal degradation mediated by a RING-type E3 ubiquitin ligase [40]. Given that MDM2 is a RING-

A
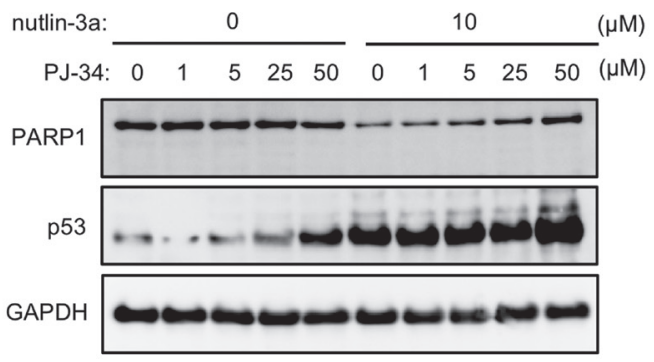

type E3 ubiquitin ligase, we hypothesize that nutlin-3ainduced allosteric changes of MDM2 could promote the autoPARylation of PARP1 possibly through the regulation of PARG.

PARP1 inhibitors disturb the single strand repair that causes persistent double strand breaks and lethality in BRCA1-deficient cancers lacking the capacity for HR repair [41-43]. However, several studies have described the limited efficacy of PARP1 inhibitors in some BRCA1 mutation carriers [44]. As a mechanism in such resistance, it has been demonstrated that ATR regulates BRCA1independent HR by activating Rad51, which constitutes a complex with other Rad proteins and BRCA1 that is important for HR [45, 46]. Yazinski also revealed that ATR inhibition overcomes PARP1 inhibitor resistance in BRCA1-deficient cells [45]. Another group also reported Rad51-mediated resistance to PARP inhibition in triple negative breast cancers and breast cancer stem cells [47]. Furthermore, Ireno and colleagues demonstrated that nutlin-3a reduces Rad51 protein levels probably in a p53-dependent manner and suppresses homologous double strand break repair frequencies. This observation is supported by another previous report showing that p53 transcriptionally downregulated $\operatorname{Rad} 51$ [48, 49]. These findings indicate that nutlin-3a could be a PARP1

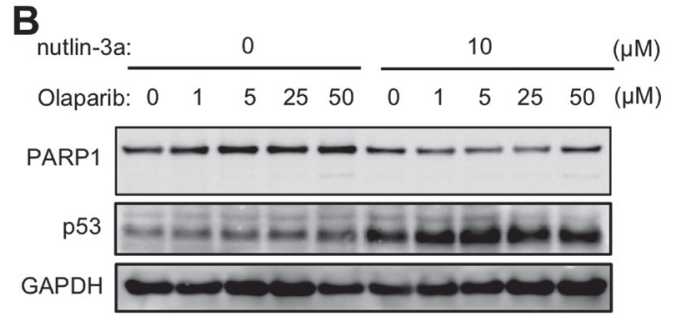

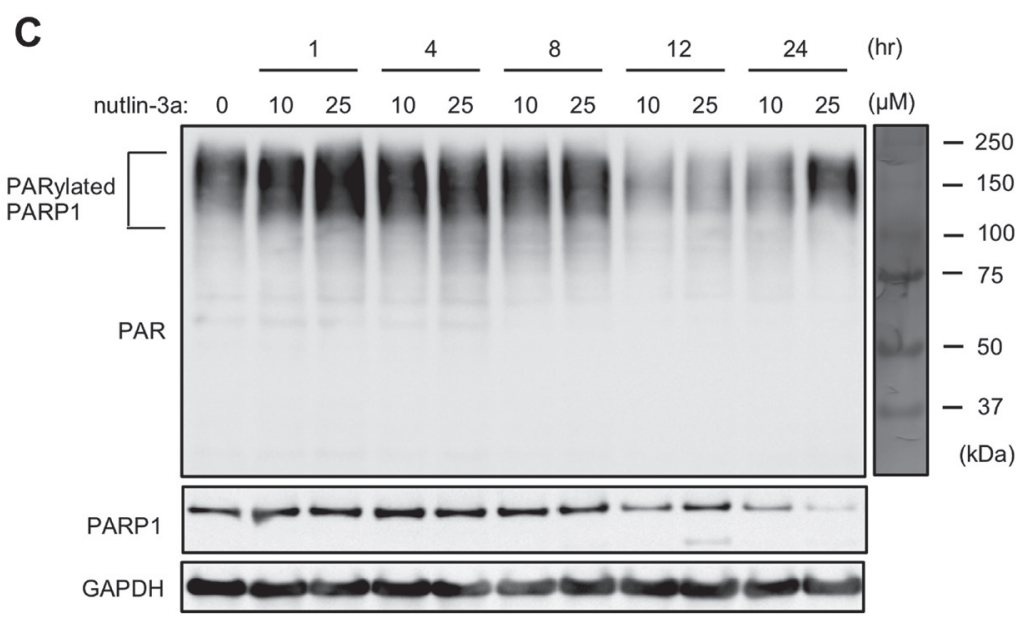

Figure 4: AutoPARylation of PARP1 plays important roles in nutlin-3a-induced PARP1 degradation. (A, B) MCF-7 cells were treated with $10 \mu \mathrm{M}$ nutlin-3a in the presence or absence of the indicated concentrations of PJ34 (A) or olaparib (B) for $24 \mathrm{~h}$. (C) MCF-7 cells were treated with 10 or $25 \mu \mathrm{M}$ nutlin-3a for indicated times. Cell lysates were analyzed by immunoblotting using indicated antibodies. GAPDH was used as a loading control. 
suppressor efficient for cancers with BRCA1 mutation and Rad51-dependent resistance to PARP1 inhibitors. Apart from the above, several reports have illustrated the tumor's resistance to PARP1 competitive inhibitors, mimics of $\mathrm{NAD}^{+}$such as olaparib and iniparib. For example, c-Met, a receptor tyrosine kinase that is overexpressed in various cancers, phosphorylates PARP1 at Tyr907 [50]. This phosphorylation causes reduced binding activity of PARP1 competitive inhibitors, which in turn develops the PARP1 inhibitor-resistance in cancer cells [50]. Additionally, another group highlighted that the loss of PARG, an enzyme responsible for degradation of PAR, is frequently observed in PARP1 inhibitor-resistant tumors [51]. PARG inactivation was also proven to cause accumulation of PAR, resulting in the disturbance of competitive inhibition of PARP1 activity [51]. Nutlin-3a may be able to avoid such PARP1 inhibitor-resistance, because nutlin-3a decreased PARP1 proteins, unlike the conventional inhibitors.

Nutlin-3a has been widely recognized as a p53 stabilizer. Our previous and present studies further demonstrate that nutlin-3a is a PARP1 suppressor with the ability to promote degradation of PARP1 protein. Moreover, we previously confirmed that Caylin2, a derivative of nutlin-3a, also induces PARP1 degradation
[52]. This finding raises the possibility of nutlin-3a as a lead compound for the identification of more potent PARP1 suppressors with distinct mechanisms from the currently available PARP inhibitors. Further analysis of the effects of nutlin-3a will be important for the development of novel strategies of refractory cancer therapy.

\section{MATERIALS AND METHODS}

\section{Cell culture and reagents}

MCF-7 cells were obtained from the American Type Culture Collection (ATCC, Manassas, VA, USA) and cultured in Eagle's Minimal Essential Medium (Wako, Osaka, Japan) with 10\% fetal bovine serum (FBS) (Thermo Fisher Scientific, Waltham, MA, USA), 1\% penicillin streptomycin (P/S) (Sigma-Aldrich, St. Louis, MO, USA), $10 \mu \mathrm{g} / \mathrm{mL}$ insulin (Wako), 1\% MEM Nonessential Amino Acids Solution (Wako) and $1 \mathrm{mM}$ Sodium Pyruvate Solution. Plat-A cells were kindly provided by Toshio Kitamura and cultured in DMEM (high glucose) with $10 \% \mathrm{FBS}, 1 \% \mathrm{P} / \mathrm{S}, 1 \mu \mathrm{g} / \mathrm{mL}$ puromycin (Wako) and $10 \mu \mathrm{g} / \mathrm{mL}$ blasticidin (Funakoshi, Tokyo, Japan). Nutlin3a was supplied by Cayman (Ann Arbor, MI, USA). The chemical structure of nutlin-3a has been shown in previous
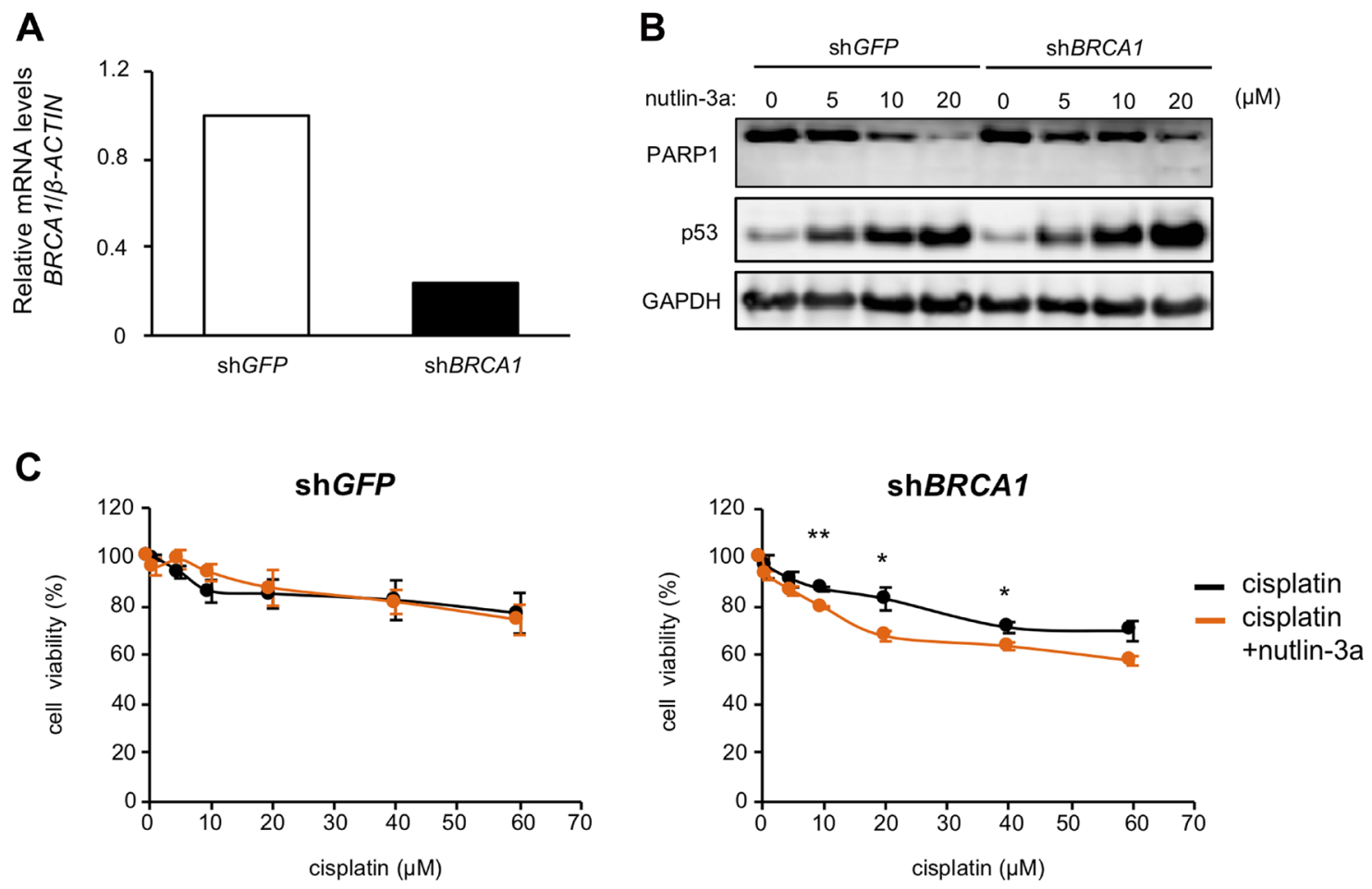

Figure 5: Nutlin-3a enhances the effect of cisplatin in BRCA1 knockdown MCF-7 cells. (A) $B R C A 1$ levels in MCF-7/sh $G F P$ and MCF-7/shBRCA1 cells were analyzed by qRT-PCR. (B) MCF-7/shGFP and MCF-7/shBRCA1 cells were treated with nutlin-3a at the indicated concentrations for $24 \mathrm{~h}$. Cell lysates were analyzed by immunoblotting using the indicated antibodies. (C) MCF-7/shGFP (left panel) and MCF-7/shBRCA1 cells (right panel) were treated with $10 \mu \mathrm{M}$ nutlin-3a. After $12 \mathrm{~h}$, the indicated concentrations of cisplatin were directly added to pretreated cells and cells were incubated for $24 \mathrm{~h}$. Cell viability was measured by WST- 8 assay. Values are means $\pm \operatorname{SEM}(n=3$; different experiments). Differences between values in each indicated concentration of cisplatin were analyzed by Student $t$ test. $\left({ }^{*} p<0.05,{ }^{* *} p<0.01\right)$. 
Table 1: Primers used in the present study

\begin{tabular}{lll}
\hline Genes & Forward $\left(\mathbf{5}^{\prime}\right.$ to $\left.\mathbf{3}^{\prime}\right)$ & Reverse $\left(\mathbf{5}^{\prime}\right.$ to $\left.\mathbf{3}^{\prime}\right)$ \\
\hline$M D M 2$ & GCTGGGAACCTCTTGATTGTG & ATCCACCCATAAAGCGCAAC \\
$C H F R$ & TTCTGTGGAGCTTTACCCTCTG & GATAAACTTGCCCTTCTCCCTTG \\
$R N F 146$ & CAAACAGGAAAGCGAACGAG & TTCTGGTGACAACAAGGTTGG \\
$B R C A 1$ & AACCAGGAGTGGAAAGGTCATC & GTTTCCGTCAAATCGTGTGG \\
$\beta$-ACTIN & TGGGACGACATGGAGAAAATC & ATAGCACAGCCTGGATAGCAAC \\
\hline
\end{tabular}

studies [25, 52]. RITA was purchased from Adooq Bioscience (Irvine, CA, USA). Olaparib was purchased from ChemScene, LLC (Monmouth Junction, NJ, USA). MG132, PJ34 and cisplatin were purchased from Wako. Cisplatin was dissolved in $90 \%$ dimethyl sulfoxide in phosphate buffered saline (90\% DMSO in PBS) before use. Other reagents were dissolved in DMSO.

\section{Establishment of MCF-7 cells expressing shRNAs}

For the p53 and BRCA1 stable KD cells, we designed human TP53 and BRCA1 target sequences and inserted the oligonucleotides into the pMXs-mU6puro plasmid, as shown in our previous report [53]. The shRNA sequences of TP53, BRCA1 and the negative control (shGFP) were as follows: shTP53 5'-GGA TTT CAT TTC TTG TGT ATG GTT CAA GAG ATC ATA TAC AAG AGA TGA AAT CCT TTT T-3' and 5'-CGA AAA AGG ATT TCA TCT CTT GTA TAT GAT CTC TTG AAC CAT ACA CAA GAA ATG AAA TCC-3', shBRCA1 5'- GAA AGA AGT GGA TTT GTC TGT TTC AAG AGA GCA GAT AAA TCC ATT TCT TTC TTT TT-3' and 5'-CGA AAA AGA AAG AAA TGG ATT TAT CTG CTC TCT TGA AAC AGA TAA ACC CAT TCC TTT C-3', and shGFP 5'-GTG CTA TTG GAG TTG ATA GTC TTC AAG AGA GAT TAT CAA TTC CAA TAG TAC CTT TTT-3' and 5'-CGA AAA AGG TAC TAT TGG AAT TGA TAA TCT CTC TTG AAG ACT ATC AAC TCC AAT AGC AC-3'. Underlined letters indicate loop structure sequences. shTP53-, shBRCA1- and shGFPexpressing MCF-7 cells were generated using a retroviral system with plat-A cells as previously reported [53]. In brief, each pMXs-mU6-puro plasmid was transfected into plat-A cells using FuGENE 6 (Promega, Tokyo, Japan). The supernatant from each virus-containing culture was collected 2 days later and concentrated with $4 \times$ PEG-it solution [32\% (w/v) PEG-6000, $400 \mathrm{mM} \mathrm{NaCl}$, and 40 $\mathrm{mM}$ HEPES, $\mathrm{pH}$ 7.4]. MCF-7 cells were incubated with virus particles for $24 \mathrm{~h}$, followed by selection with $2 \mu \mathrm{g} /$ $\mathrm{mL}$ puromycin for 5-7 days.

\section{Transfection of siRNAs}

For the MDM2, CHFR or RNF146 transient KD, we introduced two Silencer Select Pre-Designed siRNAs against MDM2 (siMDM2: s224037 and s8628), CHFR
(siCHFR: s31392 and s31393) or RNF146 (siRNF146: s37822 and s37823) (Thermo) into MCF-7 cells using Lipofectamine RNAiMAX Transfection Reagent (Thermo), respectively. Silencer Select Negative Control \#1 siRNA (Thermo) was used as a negative control. Transfection of siRNAs was performed according to the manufacturer's protocol. Cells were treated with $10 \mu \mathrm{M}$ nutlin-3a at $48 \mathrm{~h}$ after transfection of siMDM2 or $60 \mathrm{~h}$ after transfection of siCHFR or siRNF146. After $24 \mathrm{~h}$, treated cells were collected and analyzed.

\section{Immunoblotting analysis}

Immunoblotting was performed as previously reported [27]. Briefly, collected cells were lysed with SDS sample buffer [50 mM Tris- $\mathrm{HCl} \mathrm{pH} 6.8,2 \%$ SDS, $3 \mathrm{M}$ urea, $6 \%$ glycerol], boiled for $5 \mathrm{~min}$ and sonicated. Next, lysates were subjected to SDS-PAGE on $10 \%$ poly-acrylamide gels and transferred to nitrocellulose membranes. The membranes were blocked with blocking solution [2.5\% skim milk and $0.25 \%$ BSA in TTBS (50 $\mathrm{mM}$ Tris, $\mathrm{pH} 7.4,150 \mathrm{mM} \mathrm{NaCl}, 0.1 \%$ Tween 20)] for $60 \mathrm{~min}$ at room temperature and then probed with the appropriate primary antibody overnight at $4{ }^{\circ} \mathrm{C}$ : PARP1 (9532; Cell Signaling, Beverly, MA, USA), p53 (clone DO-1, OP43L; Calbiochem San Diego, CA, USA), CASP7 (9492; Cell Signaling), glyceraldehyde-3phosphate dehydrogenase (GAPDH) (sc-32233; Santa Cruz Biotechnology, San Francisco, CA, USA), or pADPr (clone 10H, sc-56198; Santa Cruz Biotechnology). The membranes were then incubated with the appropriate secondary antibody for $60 \mathrm{~min}$ at room temperature: horseradish peroxidase-conjugated $\mathrm{F}$ ( $\mathrm{ab}$ ')2 fragment of goat anti-mouse IgG (115-036-062) or anti-rabbit IgG (111-036-045) (Jackson Immuno Research, West Grove, PA, USA). Chemiluminescence was performed with ImmunoStar LD Reagent (Wako). The antibodybound proteins were visualized with an LAS3000 Image Analyzer (Fujifilm, Tokyo, Japan), and data were analyzed using Multigauge software (GE Healthcare, Madison, WI, USA). GAPDH was used as a loading control.

\section{RNA extraction and quantitative RT-PCR (qRT- PCR)}

Total RNA was extracted from cells using ISOGEN II (Nippon Gene, Tokyo, Japan) according to 
the manufacturer's protocol. Purified RNA $(0.5 \mu \mathrm{g})$ was subjected to reverse transcription with the ReverTra Ace qPCR RT Master Mix with gDNA Remover (TOYOBO, Osaka, Japan). qRT-PCR was performed using a CFX Connect ${ }^{\mathrm{TM}}$ RT-PCR System (Bio-Rad, CA, USA) with THUNDERBIRD SYBR qPCR Mix (TOYOBO). The quantitative PCR data were processed with a standard curve method. $\beta$-Actin was used for normalization. The primer sequences are shown in Table 1.

\section{Measurement of cell viability}

The number of viable cells was determined using the Cell Counting Kit-8 (DOJINDO, Kumamoto, Japan) according to the manufacturer's protocol. Briefly, cells were plated at a density of 5000 cells/well in 96-well plates. After $1-2 \mathrm{~h}$, cells were treated with $10 \mu \mathrm{M}$ nutlin$3 \mathrm{a}$ for $12 \mathrm{~h}$ and then $1,5,10,20,40$ or $60 \mu \mathrm{M}$ cisplatin was added. After 24 h, $10 \mu \mathrm{L}$ Cell Counting Kit reagent was added to wells, and cells were incubated at $37^{\circ} \mathrm{C}$ for $3 \mathrm{~h}$. Absorbance was measured at $450 \mathrm{~nm}$ using an ARVO MX/Light Wallac 1420 Multilabel/Luminescence Counter (PerkinElmer, Waltham, MA, USA). Cell viability was calculated according to the manufacturer's protocol for the Cell Counting Kit-8.

\section{Statistical analysis}

Data were statistically evaluated by the Student $t$ test, the Tukey's test or Dunnett's test using BellCurve for Excel software (Social Survey Research Information Co., Ltd, Tokyo, Japan). Data are presented as mean \pm standard error of the mean (SEM), and $p<0.05$ was considered significant.

\section{Author contributions}

Y.H. and M.K. conceived and designed the experiments and wrote the manuscript. Y.I. and M.O. performed experiments and analyzed data under M.K.'s leadership. Y.M., S.H., Y.K., R.T., N.O., K.A. and Y.S. helped with experiments and contributed to discussion.

\section{ACKNOWLEDGMENTS}

We are deeply grateful to all members of the Laboratory of Molecular Pathology and Metabolic Disease (Faculty of Pharmaceutical Sciences, Tokyo University of Science) for their cooperation. We thank Edanz Group (http://www.edanzediting.com/ac) for editing a draft of this manuscript.

\section{CONFLICTS OF INTEREST}

The authors declare no conflicts of interest.

\section{FUNDING}

M.K. was supported by Grants-in-Aid for Young Scientists (B) (No. 17K13231) from the Japan Society for the Promotion of Science. Y.H. was supported by Grantsin-Aid for Scientific Research (B) (No. 17H02179) from the Japan Society for the Promotion of Science and by the MEXT Supported Program for the Strategic Research Foundation at Private Universities, 2014-2018.

\section{REFERENCES}

1. Schreiber V, Dantzer F, Ame JC, de Murcia G. Poly(ADPribose): novel functions for an old molecule. Nat Rev Mol Cell Biol. 2006; 7:517-28. https://doi.org/10.1038/ nrm1963. [PubMed]

2. Herceg Z, Wang ZQ. Functions of poly(ADP-ribose) polymerase (PARP) in DNA repair, genomic integrity and cell death. Mutat Res. 2001; 477:97-110. https://doi. org/10.1016/S0027-5107(01)00111-7. [PubMed]

3. Gibson BA, Kraus WL. New insights into the molecular and cellular functions of poly(ADP-ribose) and PARPs. Nat Rev Mol Cell Biol. 2012; 13:411-24. https://doi.org/10.1038/ nrm3376. [PubMed]

4. Schreiber V, Amé JC, Dollé P, Schultz I, Rinaldi B, Fraulob V, Ménissier-de Murcia J, de Murcia G. Poly(ADP-ribose) polymerase-2 (PARP-2) is required for efficient base excision DNA repair in association with PARP-1 and XRCC1. J Biol Chem. 2002; 277:23028-36. https://doi. org/10.1074/jbc.M202390200. [PubMed]

5. Krishnakumar R, Kraus WL. PARP-1 regulates chromatin structure and transcription through a KDM5B-dependent pathway. Mol Cell. 2010; 39:736-49. https://doi. org/10.1016/j.molcel.2010.08.014. [PubMed]

6. Kalisch T, Amé JC, Dantzer F, Schreiber V. New readers and interpretations of poly(ADP-ribosyl)ation. Trends Biochem Sci. 2012; 37:381-90. https://doi.org/10.1016/j. tibs.2012.06.001. [PubMed]

7. Aravind L. The WWE domain: a common interaction module in protein ubiquitination and ADP ribosylation. Trends Biochem Sci. 2001; 26:273-75. https://doi. org/10.1016/S0968-0004(01)01787-X. [PubMed]

8. Altmeyer M, Messner S, Hassa PO, Fey M, Hottiger MO. Molecular mechanism of poly(ADP-ribosyl)ation by PARP1 and identification of lysine residues as ADP-ribose acceptor sites. Nucleic Acids Res. 2009; 37:3723-38. https://doi.org/10.1093/nar/gkp229. [PubMed]

9. Langelier MF, Planck JL, Roy S, Pascal JM. Structural basis for DNA damage-dependent poly(ADP-ribosyl)ation by human PARP-1. Science. 2012; 336:728-32. https://doi. org/10.1126/science.1216338. [PubMed]

10. Kang HC, Lee YI, Shin JH, Andrabi SA, Chi Z, Gagné JP, Lee Y, Ko HS, Lee BD, Poirier GG, Dawson VL, Dawson TM. Iduna is a poly(ADP-ribose) (PAR)-dependent E3 
ubiquitin ligase that regulates DNA damage. Proc Natl Acad Sci U S A. 2011; 108:14103-08. https://doi.org/10.1073/ pnas.1108799108. [PubMed]

11. Kashima L, Idogawa M, Mita H, Shitashige M, Yamada T, Ogi K, Suzuki H, Toyota M, Ariga H, Sasaki Y, Tokino T. CHFR protein regulates mitotic checkpoint by targeting PARP-1 protein for ubiquitination and degradation. J Biol Chem. 2012; 287:12975-84. https://doi.org/10.1074/jbc. M111.321828. [PubMed]

12. Ratnam K, Low JA. Current development of clinical inhibitors of poly(ADP-ribose) polymerase in oncology. Clin Cancer Res. 2007; 13:1383-88. https://doi. org/10.1158/1078-0432.CCR-06-2260. [PubMed]

13. Bryant HE, Schultz N, Thomas HD, Parker KM, Flower D, Lopez E, Kyle S, Meuth M, Curtin NJ, Helleday T. Specific killing of BRCA2-deficient tumours with inhibitors of poly(ADP-ribose) polymerase. Nature. 2005; 434:913-17. https://doi.org/10.1038/nature03443. [PubMed]

14. Farmer H, McCabe N, Lord CJ, Tutt AN, Johnson DA, Richardson TB, Santarosa M, Dillon KJ, Hickson I, Knights C, Martin NM, Jackson SP, Smith GC, Ashworth A. Targeting the DNA repair defect in BRCA mutant cells as a therapeutic strategy. Nature. 2005; 434:917-21. https:// doi.org/10.1038/nature03445. [PubMed]

15. Konecny GE, Kristeleit RS. PARP inhibitors for BRCA1/2mutated and sporadic ovarian cancer: current practice and future directions. Br J Cancer. 2016; 115:1157-73. https:// doi.org/10.1038/bjc.2016.311. [PubMed]

16. Mateo J, Carreira S, Sandhu S, Miranda S, Mossop H, Perez-Lopez R, Nava Rodrigues D, Robinson D, Omlin A, Tunariu N, Boysen G, Porta N, Flohr P, et al. DNA-Repair Defects and Olaparib in Metastatic Prostate Cancer. N Engl J Med. 2015; 373:1697-708. https://doi.org/10.1056/ NEJMoa1506859. [PubMed]

17. Brenner JC, Feng FY, Han S, Patel S, Goyal SV, BouMaroun LM, Liu M, Lonigro R, Prensner JR, Tomlins SA, Chinnaiyan AM. PARP-1 inhibition as a targeted strategy to treat Ewing's sarcoma. Cancer Res. 2012; 72:1608-13. https://doi.org/10.1158/0008-5472.CAN-11-3648. [PubMed]

18. Choi EB, Yang AY, Kim SC, Lee J, Choi JK, Choi C, Kim MY. PARP1 enhances lung adenocarcinoma metastasis by novel mechanisms independent of DNA repair. Oncogene. 2016; 35:4569-79. https://doi.org/10.1038/onc.2016.3. [PubMed]

19. Ledermann J, Harter P, Gourley C, Friedlander M, Vergote I, Rustin G, Scott CL, Meier W, Shapira-Frommer R, Safra T, Matei D, Fielding A, Spencer S, et al. Olaparib maintenance therapy in patients with platinum-sensitive relapsed serous ovarian cancer: a preplanned retrospective analysis of outcomes by BRCA status in a randomised phase 2 trial. Lancet Oncol. 2014; 15:852-61. https://doi. org/10.1016/S1470-2045(14)70228-1. [PubMed]

20. Robson M, Im SA, Senkus E, Xu B, Domchek SM, Masuda N, Delaloge S, Li W, Tung N, Armstrong A, Wu W, Goessl C, Runswick S, Conte P. Olaparib for Metastatic Breast Cancer in Patients with a Germline BRCA Mutation. N
Engl J Med. 2017; 377:523-33. https://doi.org/10.1056/ NEJMoa1706450. [PubMed]

21. Rodríguez MI, Peralta-Leal A, O’Valle F, Rodriguez-Vargas JM, Gonzalez-Flores A, Majuelos-Melguizo J, López L, Serrano S, de Herreros AG, Rodríguez-Manzaneque JC, Fernández R, Del Moral RG, de Almodóvar JM, Oliver FJ. PARP-1 regulates metastatic melanoma through modulation of vimentin-induced malignant transformation. PLoS Genet. 2013; 9:e1003531. https://doi.org/10.1371/journal.pgen.1003531. [PubMed]

22. Lee Y, Karuppagounder SS, Shin JH, Lee YI, Ko HS, Swing D, Jiang H, Kang SU, Lee BD, Kang HC, Kim D, Tessarollo L, Dawson VL, Dawson TM. Parthanatos mediates AIMP2activated age-dependent dopaminergic neuronal loss. Nat Neurosci. 2013; 16:1392-400. https://doi.org/10.1038/ nn.3500. [PubMed]

23. Malyuchenko NV, Kotova EY, Kulaeva OI, Kirpichnikov MP, Studitskiy VM. PARP1 Inhibitors: antitumor drug design. Acta Naturae. 2015; 7:27-37. https://doi. org/10.32607/20758251-2015-7-3-27-37. [PubMed]

24. Banasik M, Komura H, Shimoyama M, Ueda K. Specific inhibitors of poly(ADP-ribose) synthetase and mono(ADPribosyl)transferase. J Biol Chem. 1992; 267:1569-75. [PubMed]

25. Vassilev LT, Vu BT, Graves B, Carvajal D, Podlaski F, Filipovic Z, Kong N, Kammlott U, Lukacs C, Klein C, Fotouhi $\mathrm{N}$, Liu EA. In vivo activation of the p53 pathway by smallmolecule antagonists of MDM2. Science. 2004; 303:844-48. https://doi.org/10.1126/science.1092472. [PubMed]

26. Shangary S, Wang S. Small-molecule inhibitors of the MDM2-p53 protein-protein interaction to reactivate p53 function: a novel approach for cancer therapy. Annu Rev Pharmacol Toxicol. 2009; 49:223-41. https://doi.org/10.1146/ annurev.pharmtox.48.113006.094723. [PubMed]

27. Matsushima S, Okita N, Oku M, Nagai W, Kobayashi M, Higami Y. An Mdm2 antagonist, Nutlin-3a, induces p53dependent and proteasome-mediated poly(ADP-ribose) polymerase 1 degradation in mouse fibroblasts. Biochem Biophys Res Commun. 2011; 407:557-61. https://doi. org/10.1016/j.bbrc.2011.03.061. [PubMed]

28. Issaeva N, Bozko P, Enge M, Protopopova M, Verhoef LG, Masucci M, Pramanik A, Selivanova G. Small molecule RITA binds to p53, blocks p53-HDM-2 interaction and activates p53 function in tumors. Nat Med. 2004; 10:132128. https://doi.org/10.1038/nm1146. [PubMed]

29. Gibbs-Seymour I, Fontana P, Rack JG, Ahel I. HPF1/ C4orf27 Is a PARP-1-Interacting Protein that Regulates PARP-1 ADP-Ribosylation Activity. Mol Cell. 2016; 62:432-42. https://doi.org/10.1016/j.molcel.2016.03.008. [PubMed]

30. Ahel D, Horejsí Z, Wiechens N, Polo SE, Garcia-Wilson E, Ahel I, Flynn H, Skehel M, West SC, Jackson SP, OwenHughes T, Boulton SJ. Poly(ADP-ribose)-dependent regulation of DNA repair by the chromatin remodeling enzyme ALC1. Science. 2009; 325:1240-43. https://doi. org/10.1126/science.1177321. [PubMed] 
31. Ahel I, Ahel D, Matsusaka T, Clark AJ, Pines J, Boulton SJ, West SC. Poly(ADP-ribose)-binding zinc finger motifs in DNA repair/checkpoint proteins. Nature. 2008; 451:81-85. https://doi.org/10.1038/nature06420. [ubMed]

32. Di Giammartino DC, Shi Y, Manley JL. PARP1 represses PAP and inhibits polyadenylation during heat shock. Mol Cell. 2013; 49:7-17. https://doi.org/10.1016/j. molcel.2012.11.005. [PubMed]

33. Wallace M, Worrall E, Pettersson S, Hupp TR, Ball KL. Dual-site regulation of MDM2 E3-ubiquitin ligase activity. Mol Cell. 2006; 23:251-63. https://doi.org/10.1016/j. molcel.2006.05.029. [PubMed]

34. Nicholson J, Neelagandan K, Huart AS, Ball K, Molloy MP, Hupp T. An iTRAQ proteomics screen reveals the effects of the MDM2 binding ligand Nutlin-3 on cellular proteostasis. J Proteome Res. 2012; 11:5464-78. https://doi.org/10.1021/ pr300698d. [PubMed]

35. Meder VS, Boeglin M, de Murcia G, Schreiber V. PARP1 and PARP-2 interact with nucleophosmin/B23 and accumulate in transcriptionally active nucleoli. J Cell Sci. 2005; 118:211-22. https://doi.org/10.1242/jcs.01606. [PubMed]

36. Wang Z, Michaud GA, Cheng Z, Zhang Y, Hinds TR, Fan E, Cong F, Xu W. Recognition of the iso-ADP-ribose moiety in poly(ADP-ribose) by WWE domains suggests a general mechanism for poly(ADP-ribosyl)ation-dependent ubiquitination. Genes Dev. 2012; 26:235-40. https://doi. org/10.1101/gad.182618.111. [PubMed]

37. Kim IK, Stegeman RA, Brosey CA, Ellenberger T. A quantitative assay reveals ligand specificity of the DNA scaffold repair protein XRCC1 and efficient disassembly of complexes of XRCC1 and the poly(ADP-ribose) polymerase 1 by poly(ADP-ribose) glycohydrolase. J Biol Chem. 2015; 290:3775-83. https://doi.org/10.1074/jbc.M114.624718. [PubMed]

38. Fujimoto M, Takii R, Katiyar A, Srivastava P, Nakai A. Poly(ADP-Ribose) Polymerase 1 Promotes the Human Heat Shock Response by Facilitating Heat Shock Transcription Factor 1 Binding to DNA. Mol Cell Biol. 2018; 38:e0051-18. [PubMed]

39. Margalef P, Kotsantis P, Borel V, Bellelli R, Panier S, Boulton SJ. Stabilization of Reversed Replication Forks by Telomerase Drives Telomere Catastrophe. Cell. 2018; 172:439-453.e14. https://doi.org/10.1016/j. cell.2017.11.047. [PubMed]

40. Grady SL, Hwang J, Vastag L, Rabinowitz JD, Shenk T. Herpes simplex virus 1 infection activates poly(ADPribose) polymerase and triggers the degradation of poly(ADP-ribose) glycohydrolase. J Virol. 2012; 86:825968. https://doi.org/10.1128/JVI.00495-12. [PubMed]

41. Yap TA, Sandhu SK, Carden CP, de Bono JS. Poly(ADPribose) polymerase (PARP) inhibitors: exploiting a synthetic lethal strategy in the clinic. CA Cancer J Clin. 2011; 61:3149. https://doi.org/10.3322/caac.20095. [PubMed]
42. Leung M, Rosen D, Fields S, Cesano A, Budman DR. Poly(ADP-ribose) polymerase-1 inhibition: preclinical and clinical development of synthetic lethality. Mol Med. 2011; 17:854-62. https://doi.org/10.2119/molmed.2010.00240. [PubMed]

43. Sistigu A, Manic G, Obrist F, Vitale I. Trial watch inhibiting PARP enzymes for anticancer therapy. Mol Cell Oncol. 2015; 3:e1053594. https://doi.org/10.1080/2372355 6.2015.1053594. [PubMed]

44. Sonnenblick A, de Azambuja E, Azim HA Jr, Piccart M. An update on PARP inhibitors - moving to the adjuvant setting. Nat Rev Clin Oncol. 2015; 12:27-41. https://doi. org/10.1038/nrclinonc.2014.163. [PubMed]

45. Yazinski SA, Comaills V, Buisson R, Genois MM, Nguyen HD, Ho CK, Todorova Kwan T, Morris R, Lauffer S, Nussenzweig A, Ramaswamy $\mathrm{S}$, Benes $\mathrm{CH}$, Haber DA, et al. ATR inhibition disrupts rewired homologous recombination and fork protection pathways in PARP inhibitor-resistant BRCA-deficient cancer cells. Genes Dev. 2017; 31:318-32. https://doi.org/10.1101/gad.290957.116. [PubMed]

46. Raderschall E, Stout K, Freier S, Suckow V, Schweiger S, Haaf T. Elevated levels of Rad51 recombination protein in tumor cells. Cancer Res. 2002; 62:219-25. [PubMed]

47. Liu Y, Burness ML, Martin-Trevino R, Guy J, Bai S, Harouaka R, Brooks MD, Shang L, Fox A, Luther TK, Davis A, Baker TL, Colacino J, et al. RAD51 Mediates Resistance of Cancer Stem Cells to PARP Inhibition in Triple-Negative Breast Cancer. Clin Cancer Res. 2017; 23:514-22. https:// doi.org/10.1158/1078-0432.CCR-15-1348. [PubMed]

48. Ireno IC, Wiehe RS, Stahl AI, Hampp S, Aydin S, Troester MA, Selivanova G, Wiesmüller L. Modulation of the poly (ADP-ribose) polymerase inhibitor response and DNA recombination in breast cancer cells by drugs affecting endogenous wild-type p53. Carcinogenesis. 2014; 35:227382. https://doi.org/10.1093/carcin/bgu160. [PubMed]

49. Arias-Lopez C, Lazaro-Trueba I, Kerr P, Lord CJ, Dexter T, Iravani M, Ashworth A, Silva A. p53 modulates homologous recombination by transcriptional regulation of the RAD51 gene. EMBO Rep. 2006; 7:219-24. https://doi. org/10.1038/sj.embor.7400587. [PubMed]

50. Du Y, Yamaguchi H, Wei Y, Hsu JL, Wang HL, Hsu YH, Lin WC, Yu WH, Leonard PG, Lee GR 4th, Chen MK, Nakai K, Hsu MC, et al. Blocking c-Met-mediated PARP1 phosphorylation enhances anti-tumor effects of PARP inhibitors. Nat Med. 2016; 22:194-201. https://doi. org/10.1038/nm.4032. [PubMed]

51. Gogola E, Duarte AA, de Ruiter JR, Wiegant WW, Schmid JA, de Bruijn R, James DI, Guerrero Llobet S, Vis DJ, Annunziato S, van den Broek B, Barazas M, Kersbergen A, et al. Selective Loss of PARG Restores PARylation and Counteracts PARP Inhibitor-Mediated Synthetic Lethality. Cancer Cell. 2018; 33:1078-1093.e12. https:// doi.org/10.1016/j.ccell.2018.05.008. [PubMed] 
52. Nagai W, Okita N, Matsumoto H, Okado H, Oku M, Higami Y. Reversible induction of PARP1 degradation by p53inducible cis-imidazoline compounds. Biochem Biophys Res Commun. 2012; 421:15-19. https://doi.org/10.1016/j. bbrc.2012.03.091. [PubMed]

53. Mikami K, Okita N, Tokunaga Y, Ichikawa T, Okazaki T, Takemoto K, Nagai W, Matsushima S, Higami Y.
Autophagosomes accumulate in differentiated and hypertrophic adipocytes in a p53-independent manner. Biochem Biophys Res Commun. 2012; 427:758-63. https:// doi.org/10.1016/j.bbrc.2012.09.134. [PubMed] 